\title{
POESÍA LÍRICA DE FRANCISCO DE TERRAZAS. EDICIÓN DE LA "EPÍSTOLA" Y LOS SONETOS
}

\author{
LYRICAL POETRY BY FRANCISCO DE TERRAZAS. \\ EDITION OF THE "EPÍSTOLA" AND THE SONNETS
}

\author{
ÁngEL José FernÁndeZ \\ Universidad Veracruzana \\ angel.fernandez.arriola@gmail.com \\ orcid: 0000-0002-8671-7197
}

Resumen: Se compila y edita en este artículo la "Epístola" y los diez sonetos conocidos hasta ahora de Francisco de Terrazas ( $c a$. 1520-1580), el primer poeta novohispano. Precede a la edición de los poemas una nota introductoria, que ha tenido por objeto situar al autor y, además, proporcionar a los lectores el seguimiento y las fuentes de copia y traslado del breve conjunto de su lírica. La edición contiene un aparato de variantes y otro, con algunas notas, muy breves, con las explicaciones de su léxico. Los poemas de Terrazas se presentan ahora en sus lecciones, al parecer, definitivas.

Palabras clave: Terrazas; lírica novohispana; genealogía; siglo xvi; rastreo de fuentes primordiales.

AвSTRACT: In this paper, the reader will find a compilation and edition of "Epístola" and the only ten sonnets presently known to have been written by Francisco de Terrazas ( $c a$. 1520-1580), the first novo-Hispanic poet. The edition is preceded by a note that situates the author in his context and provides the reader with a resumé of his brief poetic work and of the sources from which the texts have been taken and edited. This edition contains an apparatus of variant readings as well as brief notes explaining lexical uncertainties. The poems are now presented in what would appear to be their definitive versions.

Keywords: Terrazas; novo-Hispanic poetry; genealogy; sixteenth century; study of primary sources.

Recepción: 12 de noviembre de 2019; aceptación: 6 de marzo de 2020. 
RAsGos DE SU GENEALOGíA*

La dinastía de los Terrazas proviene de Fregenal de la Sierra, Badajoz, Extremadura, España, en donde moraba -hacia la mitad del siglo xv- el bachiller Diego de Terrazas, pie de casa y cabeza de la familia. Su hijo Francisco, natural del sitio y nacido cerca de 1489, emigró en 1518 a Santiago de Cuba. Allí se asoció a la expedición de Hernán Cortés. Según Baudot (1988, p. 1084), a partir de entonces acompañó al futuro marqués del Valle: fue "su mayordomo inclusive, y más adelante alcalde de la Ciudad de México", en cuyo cargo estuvo en varios períodos -a partir de 1529- y "hasta su muerte". El 30 de julio de ese último año, Terrazas remitió a Cortés una extensa misiva, en donde le informaba acerca de sus funciones administrativas y de los pormenores de sus bienes de fortuna en Nueva España ${ }^{1}$. En una carta al rey Carlos V, fechada en la capital de Nueva España el primer día de junio de 1544, el conquistador Terrazas informó a su majestad que llevaba "veynte y cinco años" de residencia "en estas partes en compañía del marqués del Valle", o sea, a partir de 1519. Esta carta se había escrito desde la perspectiva de un dirigente que recomendaba al rey acciones específicas, pues le sugería tres medidas de gobierno para el bienestar y la salud del soberano: dar pueblos en encomienda "a los conquistadores que no los tienen y no quitarlos a los que los tienen"; la segunda era que no se les quitara los pueblos a los encomenderos, "porque en quitar los pueblos se disipa toda la tierra ansí naturales como pobladores y vuestra majestad pierde la rrenta que de acá tiene"; y la tercera consistía en mantener el sistema de encomiendas, pues el "estar la tierra rrepartida" era cosa muy conveniente, puesto que así se acrecentaban las rentas del rey: "porque todos los que estamos en esta tierra biuimos de acarreto de las cosas de España porque hasta la herradura y el clauo nos traen de allá con todas las cosas más con que fuimos criados"”.

Mucho agradezco los comentarios que sobre este trabajo me hicieron los profesores Bartolomé Pozuelo Calero, de la Universidad de Cádiz; Álvaro Bustos Táuler, de la Complutense de Madrid, y Martha Lilia Tenorio, de El Colegio de México; agradezco igualmente el auxilio de Yasmín Elizabeth Rojas Pérez y Stephany Luna Callejas en el cotejo de los textos.

1 Archivo General de Indias (en adelante, AGI), Portal de Archivos Españoles, Patronato, 180, R. 82, ff. 1-16.

2 "Carta de Francisco de Terrazas a Carlos V" (año 1544, estante 58, cajón 6, leg. 9), en Santiago Montoto 1927, t. 1, pp. 113-123. 
El padre de Terrazas fue privilegiado, puesto que había recibido dotación de tierras e indios en encomienda, como lo indica la real provisión remitida a la Audiencia de México desde Valladolid, de fecha 18 de septiembre de 1538 (AGI, México, 1088, L. 3, f. 206v). Para entonces, había ocupado muchos cargos en el Ayuntamiento de México; además de haber sido alcalde ordinario, fue tenedor de bienes de difuntos, diputado titular y sustituto y regidor. El primer día de enero de 1538, resultó electo alcalde ordinario de la Ciudad de México, junto con Luis de la Torre, y el día 4 siguiente, Francisco de Terrazas padre fue nombrado tenedor de los bienes de los difuntos, "para el presente año" (Actas de Cabildo... Cuarto libro 1889, pp. 111-112).

En dicho Cabildo del Ayuntamiento de la Ciudad de México se anunció su fallecimiento, según consta en el acta de la sesión del 9 de agosto de 1549 (Baudot 1988, p. 1084). Allí se asentó lo siguiente: "Este día los dichos señores justicia y regidores platicando sobre que Francisco de Terrazas, alcalde ordinario que fue de esta Ciudad, es muerto, y que para la disposición de los negocios es necesario se nombre y elija alcalde en su lugar hasta la elección del año nuevo primero que viene" (Actas de Cabildo... Quinto libro 1889, p. 266).

El padre del poeta tuvo dos matrimonios: se casó en primeras nupcias con Ana de Obregón, en fecha desconocida, con quien procreó al futuro poeta, a otros dos hijos varones y una hija, Ana de Terrazas. En segundos esponsales, Francisco de Terrazas sénior se unió en 1532 con Ana de Castro, de cuyo matrimonio nacieron cuando menos otros tres hijos varones. Hubo, pues, una doble sucesión testamentaria, como lo señaló Dorantes de Carranza (1902, p. 178). El 20 de noviembre de 1539 fue bautizada Catalina de Terrazas Castro, hija del mayordomo de Cortés y su segunda esposa: "En lunes tercero del mes, bautizó el padre Olvera a Catalina, hija de Francisco de Terrazas y de Ana de Castro, su mujer; fueron padrinos Juan Díaz del Real y su mujer y Hernán Rodríguez y Ana López"3.

Francisco de Terrazas hijo encabezó la primera generación mexicana del expedicionario, conquistador, funcionario y encomendero del mismo nombre; el futuro poeta nació en la Ciudad de México hacia 1520. Viviría en un "ambiente hol-

${ }^{3}$ Partida de bautismo de Catalina de Terrazas Castro, en Libro número 1 de bautismos de españoles, f. 43v, Archivo de la Parroquia del Sagrario Metropolitano de México. 
gado, acomodado y señorial en que transcurr[ir]ían su infancia y juventud"; su situación económica "era lo suficientemente afortunada como para permitirle una entrega fácil y libre a las Musas y a las labores líricas" (Baudot 1988, p. 1085). Dijo a este mismo propósito Dorantes de Carranza: "fue un excelentísimo poeta toscano, latino y castellano, aunque desdichado, pues no acabó su Nuevo Mundo y Conquista" (1902, pp. 178-179). En efecto, la fortuna torció su derrotero al ocurrir el fallecimiento de su padre, cuando atravesaba la primera etapa de su vida adulta, pues con la pérdida del padre también se perdieron los privilegios y derechos sobre las encomiendas recibidas por los servicios dispensados al rey. Frente a esta situación, cobraba importancia aquella carta que su padre la había dirigido al rey en junio de 1544 .

El joven Francisco de Terrazas se casó con Ana Osorio, hija del conquistador Rodrigo de Baeça, quien "tuvo en encomienda el pueblo de Teçontepec y al pueblo de Chila en la Misteca baxa”, y de su esposa Mari de Obregón. Este matrimonio procreó tres hijos: Francisco, el tercero de la dinastía en Nueva España, Luis y Pedro (pp. 179 y 310-311). Sólo se ha localizado la partida de bautizo de su hijo menor, celebrado el año 1555 en la Catedral Metropolitana de México: "En nueve días del mes de julio, bautizó el cura Maldonado a Pedro, hijo de Francisco de Terrazas y de su mujer doña Ana Osorio"4.

El escribano Sebastián Vázquez fue un personaje importante para la familia Terrazas y, en particular, para el poeta. Antes de pasar a Nueva España, Vázquez había sido oficial de secretario en Granada. El 5 de marzo de 1538 le fue concedida licencia de embarque por la Casa de Contratación de Sevilla. Entonces declaró ser hijo de Francisco y Catalina Vázquez, vecinos de aquella ciudad andaluza, y tener un título de escribano de su majestad, "fecho en Valladolid a 16 de febrero de 1537" (AGI, Portal de Archivos Españoles, Contratación, 5536, L. 5, f. 73r).

Vázquez se estableció en México, en donde se casó con Ana de Terrazas, hermana de padre y madre del poeta, y se colocó en la Real Audiencia como receptor; en esta institución trabajaría más de cuarenta años. Sebastián y Ana tuvieron al menos dos hijos, ambos nacidos en la Ciudad de México: Francisco

${ }^{4}$ Partida de bautismo de Pedro de Terrazas Osorio, en Libro número 2 de bautismos de españoles, f. 61r, Archivo de la Parroquia del Sagrario Metropolitano de México. 
Vázquez de Terrazas fue bautizado el 9 de mayo de 1542 en la Parroquia de la Asunción; fueron sus padrinos el licenciado Hernando Caballero e Inés de Obregón, su esposa ${ }^{5}$. El segundo se llamó Sebastián Vázquez de Terrazas y fue bautizado el 19 de abril de 1557 en el mismo templo, en cuya ceremonia fungieron como padrinos sus tíos maternos: el poeta Francisco de Terrazas y Ana de Osorio ${ }^{6}$. Francisco habría de contraer matrimonio con Juana Barrientos, en la Parroquia de Santa Catarina Mártir, el 4 de septiembre de 15907; con bastante anterioridad, su hermano Sebastián se había casado con Francisca de Picana, "hija legítima de Miguel Zamorano y de doña María de Picana", el 5 de noviembre de 1579; figuraron entre sus testigos don Antonio de Bazán, alguacil mayor del Santo Oficio, y el notario apostólico don Luis de Castro ${ }^{8}$.

Sebastián Vázquez actuó a lo largo de su vida como abogado de su familia política: entre 1557 y 1573 fue curador de los hijos menores de su suegro, en el pleito contra los herederos de Diego de Guevara sobre el derecho a unas casas edificadas por aquél en la Ciudad de México (AGI, Portal de Archivos Españoles, Justicia, 176, passim), y en 1575, escribió a la corte de Madrid con el afán de pedir una dádiva del rey para sus familiares, para él mismo, para su esposa e inclusive para sus hijos. Francisco de Terrazas sénior -argumentó Vázquez en su escrito- había sido "uno de los primeros y principales conquistadores de la hija Nueva España, porque pasaron a ella con el Marqués del Valle y siempre ha tenido casa poblada con armas y caballos". Vázquez pedía que se le diera a él "por jubilado del real servicio" en la Real Audiencia, y en cuanto que se hallaba "muy pobre" y padecía "extrema necesidad por no tener con qué sustentar su casa, mujer e hijos", demandaba "quinientos pesos de oro común en cada un año por los días de su vida y de Ana de Terra-

5 Acta de bautismo de Francisco Vázquez de Terrazas, en Libro número 1 de bautismos, f. 97v, Archivo de la Parroquia del Sagrario Metropolitano de México.

${ }^{6}$ Acta de bautismo de Sebastián Vázquez de Terrazas, en Libro número 2 de bautismos, f. 81r, Archivo de la Parroquia del Sagrario Metropolitano de México.

7 Acta de matrimonio de Francisco Vázquez de Terrazas con Juana de Barrientos, en Libro número 1 de matrimonios (años 1589-1616), f. 11v, Archivo de la Parroquia de Santa Catarina Mártir de la Ciudad de México.

8 Acta de matrimonio de Sebastián Vázquez de Terrazas con doña Francisca de Picana, en Libro número 2 de matrimonios (años 1575-1815), f. 64v, Archivo de la Parroquia de la Asunción del Sagrario Metropolitano de México. 
zas, su mujer", esto último a título de que era "hija de conquistador". Esta solicitud tuvo como respuesta que se expidiera a la familia una "cédula de recomendación ordinaria", fechada en Madrid, el 25 de mayo de 1580 (AGI, Portal de Archivos Españoles, Patronato, 74, N. 1, R. 8, ff. 1-49). El poeta Terrazas y su familia debieron atravesar, ya en los años maduros e inclusive poco antes de su deceso, por necesidades muy semejantes a las de su cuñado y hermana.

El 16 de diciembre de este último año de 1580, la Audiencia de México anunció al rey el fallecimiento del poeta Francisco de Terrazas, quien al morir "dejó mujer e hijos" e inconcluso el más ambicioso de sus poemas: Nuevo Mundo y Conquista (AGI, Audiencia de México, 70, R. 1, f. 1r; fuente citada por Baudot 1988, p. 1086).

\section{APUNTES SOBRE SU POESÍA LÍRICA}

A la luz de su exigua producción poética, y a falta de mayores datos sobre su vida y obras, a Francisco de Terrazas se le puede ubicar, estilísticamente, al lado de los poetas españoles italianizantes y como voz anunciadora de los del Siglo de Oro. $\mathrm{Su}$ expresión es, como la de aquéllos, petrarquista; pero su modelo y su visión han sido confraternos de los de Garcilaso de la Vega. Terrazas ha escrito, asimismo, en octosílabos, como Garcilaso y Boscán; como éste, "al estilo antiguo”, y como Garcilaso y los futuros poetas áureos, según lo ha explicado Elías L. Rivers, toda vez que Terrazas experimentó en sus formas: compuso en octavas reales (ottava rima) el poema inconcluso Nuevo Mundo y Conquista; escribió también en tercetos encadenados (terza rima); utilizó éstos en su "Epístola"; arregló las décimas con las que polemizó con Hernán González de Eslava y, cuando menos, fue autor de los diez sonetos hasta ahora conocidos. Terrazas fue, si atendemos a lo anterior, un poeta ecléctico: estaba a la moda, al echar mano, sobre todo, de "la nueva versificación endecasílaba"; pero no abandonó los moldes de la tradición castellana (véase Garcilaso de la Vega 2001, p. 22).

Muy poco tiempo después del arraigo de la poética petrarquista en la Península Itálica se diseminó por la Ibérica, y de allí se trasladó para sentar sus reales en las tierras americanas. Resultan claros en la poesía de Terrazas "ciertos modos con- 
ceptistas o epigramáticos", acompañados de rasgos como el platonismo o el sentimentalismo, aún sin abandonar los giros sentenciosos e irónicos, hasta tornarse lo expresado "en modelo de vida y conducta" y en "espejo del verdadero amor" (Petrarca 1976, t. 1, pp. 21-23).

La simbiosis de aspectos en apariencia contradictorios nos permite afirmar una suposición de cortesanía, un atisbo incipiente de romanticismo y la presencia de un sutil erotismo en la vena poética de Terrazas, sobre todo cuando lograba colocar en la persona del yo lo experimentado, lo sentido y lo vivido por el individuo, quien, en cuanto tal, además de asumir estas pulsiones las denunciaba ante el mundo.

Como se ha visto, el artista indagó en las formas: afinó su estilo, notable sobre todo en la perfección de los sonetos. Éste ha sido su modelo creativo peculiar: en un paso A planteaba una situación, por lo regular mediante la fórmula conceptual o por medio de un sistema simbólico comparativo, casi siempre en el espacio del primer cuarteto; esto era desarrollado en lo restante del espacio textual, a lo largo del segundo cuarteto e inclusive hasta el contenido del primer terceto; de allí daba el paso $\mathrm{B}$, cuando el yo tomaba la palabra, y a partir de allí vinculaba las situaciones previa y final, equiparándolas, y en donde remataba con su experiencia mayestática a modo de conclusión y mensaje contundente. Terrazas compuso, en consecuencia, sonetos ejemplares.

En torno a esta combinación de elementos surgía, casi siempre por medio del alto contraste, el valor estético y la elevación poética de su expresión. Su estilo fue clásico, al mismo tiempo que innovador e inclusive barroco, como cuando empleó, en el soneto que comienza "La diosa que fue en Francia celebrada...", el recurso de la cifra, muy frecuentado y comprometido más tarde por los poetas del Siglo de Oro, como en parte lo ha explicado, aunque con hondura, el profesor Bustos Táuler (2003, pp. 7-10), quien logró dilucidar en el discurso "cifrado" el nombre de Isabel, la amada del poeta Terrazas. Bustos Táuler, por lo demás, acertó en señalar como anticipativa del recurso la poesía latina de Francisco de Pacheco, pero no alcanzó a despejar el locus amœenus originario de la amada, expresado igualmente en cifra en el verso final del soneto: "¡oh, más que venturoso, húmedo llano!" (p. 7). La patria de origen de la Musa ha sido, a todas luces, la meseta de Anáhuac y, con toda probabilidad, la Ciudad de México. 
El corpus óptimo de la Poesía lírica de Francisco de Terrazas se ha formado, hasta ahora, con las piezas incluidas en tres cancioneros manuscritos. El más antiguo es el Cancionero sevillano de Toledo, compuesto -según sus editores modernos- hacia la década de 1560-1570, hoy depositado en la Biblioteca de Castilla-La Mancha ${ }^{9}$; sigue a éste la versión paleográfica y transcrita después a máquina por Antonio Paz y Meliá, titulada Flores de baria poesía, de fecha 1577, manuscrito al parecer preparado por Juan de la Cueva, quien tras su breve estancia en Nueva España lo llevó consigo a la metrópoli. Este manuscrito original, hoy casi ilegible, se halla bajo custodia en los fondos de la Biblioteca Nacional de España, en Madrid ${ }^{10}$. El tercero es el manuscrito inédito del [Cancionero], formado hacia 1600, supuestamente de origen peninsular, leonés o extremeño, tal como se consigna en su descripción técnica: una pieza invaluable perteneciente desde 1973 a la University of Pennsylvania, incorporada a su Rare Book Collection; se trata del volumen catalogado últimamente como UPenn Ms. Codex 193, el cual había tenido con anterioridad la signatura Spanish 56, como señaló, en su momento, Pedro Lasarte ${ }^{11}$.

Completan esta escasa obra poética los fragmentos del poema épico Nuevo Mundo y Conquista, dado a conocer -intercalado en su crónica- por Baltasar Dorantes de Carranza en la Sumaria relación de las cosas de la Nueva España, terminada de escribir hacia 1604, donde presumiblemente se le habrían añadido partes arregladas por otros poetas, mezcladas o yuxtapuestas con lo escrito por Terrazas. Concluye el corpus con una centena de versos repartida en diez décimas tradicionales, de tipo reflexivo y tema teológico, dividida en un par de tiradas con el tema de la "Ley de Moisés": la primera como "Respuesta" al reto lanzado por Hernán González de Eslava "Sobre si la Ley de Moisén es buena o no", resuelta por el novohispano en cuatro décimas; la segunda, a modo de "Respuesta y conclusión" a la réplica de González de Eslava acerca de lo dicho por Terrazas en su "Respuesta", formada por el breve conjunto de otras seis décimas.

9 Véase la edición de 2006 a cargo de José J. Labrador Herraiz, Ralph A. DiFranco y Juan Montero, con prólogo de Begoña López Bueno, pp. 17 ss. En adelante, se citará por CST 2006.

10 Véase la ficha completa infra, en "Referencias".

11 Se citará C 193 (1600). Cf. Pedro Lasarte 1997, pp. 49 ss. 
Margit Frenk ha hecho pormenorizada revisión de este debate poético -celebrado en 1563-, a consecuencia del cual sus protagonistas pasaron recluidos una temporada en la cárcel del Santo Oficio. La filóloga lo fundamentó teniendo como base la copia hecha del original de Terrazas por su cuñado Sebastián Vázquez, quien lo remitió a la Inquisición "en cumplimiento del Edicto de Gracia promulgado por el flamante primer Inquisidor, Moya de Contreras, el 4 de noviembre de 1571", y a quien "se la presentó en febrero de 1572, junto con un informe" (cf. González de Eslava 1989, pp. 439-448), con el propósito de desahogar la causa en contra de Terrazas ${ }^{12}$.

Todos los impresos posteriores con los poemas de Terrazas deberán remitirse a los hallazgos de estas fuentes primordiales, y a éstas he acudido para presentar la primera edición moderna de la lírica del más antiguo poeta novohispano. Consulté la edición impresa en 2006 del Cancionero sevillano de Toledo, pues perfecciona las transcripciones realizadas en Madrid por Pedro Henríquez Ureña, difundidas desde las páginas misceláneas de la Revista de Filología Española en 1918 y copiadas luego por Castro Leal en Poesías. En su devenir, el Cancionero sevillano de Toledo ha tenido algunas vicisitudes: se le ha creído elaborado en Sevilla, de donde pasó a Toledo y, desde allí, se envió hacia el año 1900 a la Biblioteca Nacional de Madrid, donde se le impuso la signatura Ms. 19,661; en el año 1924 se le restituyó a Toledo y se incorporó a la antigua Biblioteca Arzobispal formada por Juan Antonio de Lorenzana y Butrón, quien al dejar el Arzobispado de México en 1771 se trasladó al año siguiente a la titularidad de la Arquidiócesis de Toledo (CST 2006, p. 17). El hecho de haber pertenecido este códice al arzobispo Lorenzana podría correlacionarlo con la poesía hecha en la Nueva España y también justificar, en gran medida, la inclusión en muchos de sus folios de algunas de las piezas arregladas en el Nuevo Continente.

Henríquez Ureña, al entresacar del Cancionero sevillano de Toledo los poemas de Terrazas, ubicó al poeta en el ámbito de la poesía del entorno, y revisó asimismo a quienes divulgaron sus obras y ensancharon su fama -entre otros, como es bien sabi-

12 Véase Archivo General de la Nación, ramo Inquisición, t. 222, ff. 206r-208r. Edmundo O’Gorman (1940, pp. 600-609) publicó la copia hecha por Sebastián Vázquez en Boletín del Archivo General de la Nación, y ANTONio Castro Leal (1940) reprodujo las décimas en Revista de Literatura Mexicana y en Francisco de Terrazas 1941, pp. 17-21. 
do, Miguel de Cervantes, Joaquín García Icazbalceta (véase su estudio de 1884), Francisco A. de Icaza, Alfonso Reyes o Bartolomé José Gallardo. Henríquez Ureña también rastreó las piezas del poeta en el manuscrito de Flores de baria poesía-cuando ambos veneros se alojaban entonces en el recinto de la Biblioteca Nacional de Madrid-y las transmitió a las letras mexicanas. Así, además de dar a conocer la "Epístola" y los cuatro sonetos incluidos en el códice de Sevilla, los relacionó con los otros cinco registrados en el manuscrito 2,973, o sea en Flores de baria poesía, y reprodujo además dos de los sonetos allí conservados, aunque poco conocidos hasta ese momento, los que comienzan "Soñé que de una peña me arrojaba..." y "Royendo están dos cabras un nudoso..." (1918, pp. 50-51).

Finalmente, he decidido cotejar las versiones de los sonetos compiladas por Bartolomé José Gallardo, cuyos primeros versos son "Dejad las hebras de oro ensortijado...", “¡Ay, basas de marfil, vivo edificio...!" y "El que es de algún peligro escarmentado...", por provenir del manuscrito de Flores de baria poesía, aparecidos en Ensayo de una biblioteca española de libros raros y curiosos, cuya publicación fue preparada por Manuel Remón Zarco del Valle y José Sancho Rayón en $1863^{13}$.

Se ha consultado de igual modo la edición crítica de Flores de baria poesía preparada por Margarita Peña en 1980, para acarrear al conjunto poético de Terrazas los cinco sonetos contenidos en sus folios. Finalmente, Pedro Lasarte (1997) ha llamado la atención sobre la importancia del códice hoy denominado UPenn Ms. Codex 193, auténtica rareza entre las letras novohispanas, en cuyo contenido, a despecho de los defectos de su clasificación técnica, figuran muchos poemas de Mateo Rosas de Oquendo -de origen peninsular e inmigrante de América, donde fue vecino en Lima y la Ciudad de México- y algunas obras del propio Terrazas y de otras voces paisanas desconocidas, como las de los novohispanos Pedro de Ledesma y José de Arrázola. Lasarte localizó en el manuscrito de Pennsylvania tres sonetos de Terrazas: las versiones poco vistas de los sonetos ya citados: "Soñé que de una peña me arrojaba..." y "Royendo están dos cabras un ñudoso...", además del soneto desconocido y nunca compilado, cuyo primer verso es "Aquella larga

13 Véase "1046.- Flores de varia poesía, recogidas de varios poetas españoles”, columnas 1003-1008. 
mano que reparte...” (pp. 47-49; véase también Tenorio 2010, t. 1, pp. 186-187).

Hasta el momento, el corpus lírico de Francisco de Terrazas se compone por la "Epístola" y una decena de sonetos, cuya lectura en nuestro tiempo desautoriza en forma categórica la "medianía" impuesta al primer poeta novohispano por la rudeza innecesaria de don Marcelino Menéndez y Pelayo (1893, t. 1, pp. $\mathrm{xxx}$ ss.).

\section{Criterios de EDición}

Con la finalidad de fijar las versiones definitivas de los poemas líricos de Terrazas, se han cotejado las versiones contenidas en Flores de baria poesía (las manuscritas por don Antonio Paz y Meliá en 1801 y las impresas por Margarita Peña en 1980); las localizadas en el Cancionero sevillano de Toledo. Manuscrito 506 (2006) y en el Cancionero (UPenn Ms. Codex 193), así como las versiones transcritas por Bartolomé José Gallardo en Ensayo de una biblioteca española de libros raros y curiosos (1863), por Pedro Henríquez Ureña en "Nuevas poesías atribuidas a Terrazas” (1918) y por Antonio Castro Leal en Poesías (1941). Se ha modernizado la escritura, puntuación y ortografía, siempre y cuando no altere la cuenta silábica ni la rima de los versos.

\section{REFERENCIAS}

\section{Corpus}

Cancionero sevillano de Toledo. Manuscrito 506 (Fondo Borbón-Lorenzana). Biblioteca de Castilla-La Mancha 2006. Eds. José J. Labrador Herraiz, Ralph A. DiFranco y Juan Montero. Prol. Begoña López Bueno, Universidad de Sevilla, Sevilla.

Dorantes de Carranza, Baltasar 1902. Sumaria relación de las cosas de la Nueva España, con noticia individual de los descendientes legítimos de los conquistadores y primeros pobladores españoles. Pról. y apéndice de Luis González Obregón, paleografía de José María Ágreda y Sánchez, Imprenta del Museo Nacional, México.

Flores / de / baria poesía recoxida de varios / poetas españoles. Divídese en cinco / libros como declara en la tabla / que inmediatamente va aqui scripta. / Recopilóse en la Ciudad de México. Anno del nasci- / miento de Nuestro Salvador / Jesuchristo de 1577 / annos. Ms. 7982 de la Biblioteca Nacional de España 
[Mss. MICRO / 807 (1801)], transcrito por don Antonio Paz y Meliá, Parte 1, ff. i-ii + ff. 1-131; Parte 2, ff. 132-266.

Flores de baria poesía 1980. Ed. Margarita Peña, Universidad Nacional Autónoma de México, México.

Gallardo, Bartolomé José 1863. Ensayo de una biblioteca española de libros raros y curiosos, formado con los apuntamientos de don Bartolomé José Gallardo, coordinados y aumentados por don Manuel Remón Zarco del Valle Espinosa de los Monteros y don José Sancho Rayón, Imprenta y Estereotipia de M. Rivadeneyra, Madrid.

Henríquez Ureña, Pedro 1918. "Nuevas poesías atribuidas a Terrazas", Revista de Filología Española, 5, pp. 49-56.

Terrazas, Francisco De 1941. Poesías. Ed., pról. y notas de Antonio Castro Leal, Librería de Porrúa Hermanos y Compañía, México. (Biblioteca Mexicana, 3).

\section{Archivos}

Archivo General de Indias (AGI).

Archivo General de la Nación.

Archivo de la Parroquia de la Asunción del Sagrario Metropolitano de México.

Archivo de la Parroquia del Sagrario Metropolitano de México.

Archivo de la Parroquia de Santa Catarina Mártir de la Ciudad de México.

\section{Referencias bibliográficas}

Actas de Cabildo de la Ciudad de México. Cuarto libro 1889. [Paleografiado por Manuel Orozco y Berra. Año 1859]. Ed. Ignacio Bejarano, Municipio Libre, México.

Actas de Cabildo de la Ciudad de México. Quinto libro 1889. [Paleografiado por Antonio Espinosa de los Monteros. Año 1862]. Ed. Ignacio Bejarano, Municipio Libre, México.

Baudot, Georges 1988. "Lupercio Leonardo de Argensola continuador de Francisco de Terrazas. Nuevos datos y documentos", Nueva Revista de Filología Hispánica, 36, 2, pp. 1083-1091; doi: 10.24201/nrfh.v36i2.712.

Bustos Táuler, Álvaro 2003. "Francisco de Terrazas, poeta toscano, latino y castellano", Dicenda. Cuadernos de Filología Hispánica, 21, pp. 5-19.

Castro leal, Antonio 1940. "Unos versos desconocidos de Francisco de Terrazas y un falso privilegio", Revista de Literatura Mexicana, 2, pp. 348362.

García Icazbalceta, JoaQuín 1884. "Literatura mexicana. Francisco de Terrazas y otros poetas del siglo xvı", en Memorias de la Academia Mexicana correspondiente de la Real Española, Imprenta de Francisco Díaz de León, México, t. 2, pp. 357-425. 
GonzÁlez de Eslava, Fernán 1989. Villancicos, romances, ensaladas y otras canciones devotas. Ed. crít., introd., notas y apéndices de Margit Frenk, El Colegio de México, México. (Biblioteca Novohispana, 1).

Lasarte, Pedro 1997. "Francisco de Terrazas, Pedro de Ledesma y José de Arrázola: algunos poemas novohispanos inéditos", Nueva Revista de Filología Hispánica, 45, 1, pp. 45-66; doi: 10.24201/nrfh.v45i1.1971.

Menéndez y Pelayo, Marcelino 1893. Antología de poetas hispano-americanos. T. 1: México y América Central, Establecimiento Tipográfico "Sucesores de Rivadeneyra", Madrid.

Montoto, Santiago (recop.) 1927. Colección de documentos inéditos para la historia de Ibero-América, t. 1, Editorial Ibero-Africano-Americana, Madrid.

O'Gorman, Edmundo 1940. "Dos documentos de nuestra historia literaria (siglo XVI)", Boletín del Archivo General de la Nación, 11, pp. 593-616.

Petrarca, Francesco de 1976. Poesía completa. El cancionero. Trad. y prol. Atilio Pentimalli, Ediciones 29, Barcelona, 2 ts.

Tenorio, Martha Lilia 2010. Poesía novohispana. Antología. Presentación de Antonio Alatorre, El Colegio de México-Fundación para las Letras Mexicanas, México, 2 ts.

Vega, Garcilaso de la 2001. Poesías castellanas completas. Ed., introd. y notas de Elías L. Rivers, Castalia, Madrid.

\section{Abreviaturas de las fuentes}

CST 2006 Cancionero sevillano de Toledo. Manuscrito 506 (1560-1570) [2006].

APM 1801 Flores de baria poesía, transcripción de Antonio Paz y Meliá (1577/ 1801).

C 193 (1600) [Cancionero]. Ms. Codex 193 (1600), University of Pennsylvania, Rare Book Collection.

BJG 1863 Ensayo de una biblioteca española de libros raros y curiosos (1863).

PHU 1918 "Nuevas poesías atribuidas a Terrazas", por Pedro Henríquez Ureña (1918).

ACL 1941 Poesías, edición de Antonio Castro Leal (1941).

FBP 1980 Flores de baria poesía, edición de Margarita Peña (1980).

$D A$

Diccionario de autoridades, RAE-J de J Editores, Madrid, 2013 [1726-1737], 6 ts. [Ed. facs. con motivo del III Centenario]. 


\section{E P Í S T O L A*}

Pues siempre tan sin causa pretendiste ver acabar en tanto descontento esta vida cansada, dura y triste,

no puede ser que no te dé contento

5 saber, de[s]pués que en esta carta veas, el punto en que me tiene mi tormento.

Suplícote, señora, que la leas, pues ha de ser el fin de importunarte, y no dudes que ves lo que deseas.

10 Muy bien puedes echar penas aparte, y en verme haber venido a tal estado de ser más enojada asegurarte,

si acaso no te enojo, en que he llegado al extremo del mal que me buscaste,

$15 \mathrm{y}$ en que [he] con lo que quieres, acertado.

Alégrate, si nunca te alegraste con mi memoria, pues la causa nueva te da cuantos efectos deseaste.

No pienses que te escribo por que mueva

20 tu fiero corazón el dolor mío, que ya de su dureza ha hecho prueba.

Mas porque en ver mi carta, yo confío -iqué digo confiar: que desespero!aquí conocerás que desvarío.

25 Confío que en sabiendo cómo muero has de quedar, señora, tan contenta cuanto quejoso yo en no ser primero.

Quisiera, ya que quieres que consienta mi mal, saber la causa que te hace

* CST 2006, ff. 268r-271r, pp. 258-260, con el título "153. Epístola de Francisco de Terrasas". Otras Fuentes: PHU 1918, pp. 52-54, con el título "Epístola, de Francisco de Terrasas", y ACL 1941, pp. 12-16, con el título "Epístola".

6 punto: "asunto o materia de que se trata" (DA, t. 5 [1737]).

12 Se sugiere una lectura de los vv. 10-12: 'Puedes desentenderte de mí; pero date cuenta de cómo te importuno para que te enojes conmigo todavía más'.

${ }^{26}$ has: cas, por errata PHU 1918. 
30 continuo de mi muerte tan hambrienta, porque si por ventura satisface alguna culpa mía aquesta pena, no diga que es por sólo que te place.

Mas es de razón cosa muy ajena

35 buscar en tu querer ya más razón que saña y desamor que me condena.

¡Oh, cuántas veces vide en mi pasión tu libre voluntad esquiva y dura, vestida con engaños de ocasión!

40 Y viendo el fin de tanta desventura, con falsas esperanzas sustentaba la vida ya deshecha de tristura.

Con cuántas conjeturas me engañaba -al menos procuraba de engañarme-,

45 en tanto que el dolor más aquejaba.

Mil veces, viendo ya desesperarme, dije: "no puede ser que dure tanto, que no se acabe el mal con acabarme".

Esto me causa ahora nuevo espanto,

50 que no sé yo, muriendo, cómo vivo, si no es a pura fuerza de mi llanto.

Ni siento ya qué digo ni qué escribo, mas hago aquí testigo al alto cielo de tanta sinrazón como recibo.

55 Una cosa me daba algún consuelo, y era creer que te contentarías con ver teñir mi sangre el duro suelo.

Si es aquesto así, qué más porfías, qué más puedes querer; yo no lo siento,

60 habiendo visto ya lo que querías.

Mas muerte ni dolor ni sentimiento jamás hartar pudieron tu deseo,

${ }^{30}$ continuo: contino CST 2006 | PHU 1918 | ACL 1941 || continuo: "Continuamente" (DA, t. 2 [1739]).

35 ya: yo PHU 1918|ACL 1941.

42 deshecha: desecha CST 2006 | PHU 1918 || tristura: voz anticuada: "Tristeza" (DA, t. 6 [1739]). Véase v. 91.

${ }^{52}$ Ni: No ACL 1941.

58 porfías: "importunas" (DA, t. 5 [1737]).

59 qué: y qué PHU 1918. 
y menos acabar mi sufrimiento.

Yo sé, señora, cierto; yo lo creo,

65 si vieses que tal es mi triste vida

en esta sepultura en que me veo,

que ya que esa alma fiera, endurecida,

a compasión ninguna se moviese,

al menos mi pasión sería creída.

70 Estoy adonde, ya que me muriese, iría el alma bien aventurada, si lo que aquí por ti, por Dios sufriese.

Vivo una vida aquí desesperada, fuera del trato humano de la gente,

75 do solos muertos hacen su morada.

Querría el corazón del mal que siente dar cuenta, mas ni sabe ni podría; baste de ti, señora, estar ausente.

Baste que se me acuerda que solía

80 un tiempo venturoso en sólo verte, ser otro del que ahora en alegría.

Baste que tardará poco mi muerte, aunque a la vida dice el [e] speranza que no me quieres ver, por no dolerte.

85 ¿Qué buen imaginar, qué confianza, que en ti quepa dolor de mi cuidado, si buscas en mi muerte tu venganza!

Huelga, pues llega ya aquel deseado tiempo en que de esta triste sepultura

90 seré para la tierra trasladado,

64 cierto: "vale lo mismo que cierta y verdaderamente" (DA, t. 2 [1729]).

66 sepultura: sepoltura CST 2006|PHU 1918.

67 fiera: fuera, por errata ACL 1941.

68 Add. y ACL 1941.

71 iría: irá, por errata PHU 1918|ACL 1941.

86 cuidado: "recelo y temor de lo que puede sobrevenir" (DA, t. 2 [1729]).

88 Huelga: "tener gusto y placer de alguna cosa" (DA, t. 4 [1734], s.v. holgar).

${ }^{89}$ sepultura: sepoltura CST 2006| PHU 1918. 
adonde podrá ser que la tristura me deje, como en esta vida han hecho el bien, el alegría y la ventura.

Un solo dolor rompe ahora el pecho,

95 que es no te poder ver antes que muera; mas aún espero haber otro provecho, que es, que aunque tu saña no lo quiera, podrás pisar, pasando descuidada, la tierra do estará mi carne fiera,

100 y esto hará mi alma descansada.

PARTE MÁS PRINCIPAL DE ESTA ALMA VUESTRA...*

Parte más principal de esta alma vuestra, beldad que sola fue sobre natura, retrato de la suma hermosura sacado al natural por mano diestra.

$5 \quad$ La fuerza del deseo, que me adiestra continuo a lo imposible, y lo procura, me hace que a pesar de la ventura quiera lo que a querer Amor me muestra.

Y tiéneme en extremo la porfía,

10 que no puede alcanzar el sentimiento, que más que veros quiere el alma mía.

Efectos son del loco atrevimiento; mas pues no llega al bien la fantasía, con sólo desearlo me contento.

100 Se sugiere una lectura de los vv. 94-100: 'Lo único que me aflige es no poder verte antes de que me muera; pero todavía espero alcanzar el beneficio de que, sin tú saberlo, pises mi sepultura'.

* CST 2006, f. 271v, pp. 260-261, con el título "154. Soneto del dicho. [Francisco de Terrazas]". Otras Fuentes: PHU 1918, pp. 54-55, con el título "Soneto, del dicho [Francisco de Terrazas]", y ACL 1941, p. 7, con el numeral "V".

${ }^{6}$ continuo: contino CST 2006 | PHU 1918 | ACL 1941 || continuo: "Lo mismo que siempre o continuamente" (DA, t. 2 [1729]).

8 Amor: amor PHU 1918|ACL 1941.

9 tiéneme: "Asir, o mantener asida alguna cosa" (DA, t. 6, [1739], s.v. tener) || porfía: "Contienda o disputa de palabras, tenaz y obstinada" (DA, t. 5 [1737]). 
CUANDO LA CAUSA BUSCO DEL EFEGTO...*

Cuando la causa busco del efecto que lleva un desear a lo imposible, hallo que a sólo Amor todo es posible, y el cómo no lo alcanza mi concepto.

¡Oh, gran poder de Amor, cuyo secreto a nadie puede ser comprehensible! ¿Qué más quiere el querer, ¡oh, caso horrible!, que el mísero vivir tiene en aprieto?

Pues si ha hallado el fin que un alma quiere

10 mi loco atrevimiento, y más procura que ver el solo bien del alma mía,

será porque ha ganado, si muriere -aunque el morir castiga su locurala gloria del deseo, mi porfía.

\section{SONETO A UNA SANGRÍA*}

La mano que os dejó de una sangría en un punto mortal desfigurada, no fuera tan crüel, ni tan pesada, si le doliera veros cual os vía.

Mirara al menos bien cómo rompía, señora, vuestra vena delicada, ya que para salud tan desëada el precio de tal sangre convenía.

* CST 2006, f. 272r, p. 261, con el título "155. Soneto del dicho. [Francisco de Terrazas]". Otras fuentes: PHU 1918, p. 55, con el título "Cuando la causa busco del efecto...", y ACL 1941, p. 10, con el numeral "VIII".

3 Amor: amor PHU 1918|ACL 1941.

5 Amor: amor PHU 1918| ACL 1941.

14 porfía: "Significa también la continuación o repetición de una cosa muchas veces, con ahínco y tesón”; "se llama también la instancia e importunación para el logro de alguna cosa" (DA, t. 5 [1737]).

* CST 2006, f. 272v, pp. 261-262, con el título "156. Soneto a una sangría, del dicho. [Francisco de Terrazas]". Otras fuentes: PHU 1918, pp. 55-56, con el título "Soneto a una sangría, del dicho", y ACL 1941, p. 8, con el título "VI. A una sangría".

5 Mirara: Mirad ACL 1941. 
Mas yo pienso que es pena de pecado

10 el no dolerle así vuestra herida, de no doleros vos de mi cuidado.

Aunque también no es pena merecida que aquel por daros vida os ha llagado, y vos por mayor bien quitáis la vida.

\section{LA DIOSA QUE FUE EN FRANCIA CELEBRADA...*}

La diosa que fue en Francia celebrada, de quien su gran ciudad se llama ahora, y el hombre que de mano matadora primero padeció la muerte airada,

formaron de sus nombres el que agrada al alma, que la de él quiere y adora; natura le empleó luego a la hora en la que de ninguna fue igualada.

En parte le empleó, que es el traslado

10 de la beldad del cielo, propiamente, hecha a su semejanza y por su mano.

Quien fruto produció tan extremado, de ti decirse sólo se consiente, ¡oh, más que venturoso, húmedo llano!

10 herida: la $h$ bebe aspirarse, tal como se pronunciaba en la época del autor.

" CST 2006, f. 273r, p. 262, con el título "157. Soneto del dicho. [Francisco de Terrazas]". Otras fuentes: PHU 1918, p. 56, con el título "Soneto, del dicho", y ACL 1941, p. 11, con el numeral "IX".

${ }^{9}$ le: lo ACL 1941.

13 consiente: "Convenir con el dictamen o parecer de otro" (DA, t. 2 [1729], s.v. consentir).

${ }^{14}$ A diferencia de Álvaro Bustos Táuler (2003, p. 7) o de Martha Lilia Tenorio (2010, t. 1 , p. 186, n. 8), propongo como lugar de origen de Isabel, la Musa de Terrazas, la Ciudad de México, por estar asentada esta metrópoli y haber sido fundada sobre el área lacustre de la Meseta de Anáhuac. 
DEJAD LAS HEBRAS DE ORO ENSORTIJADO...*

Dejad las hebras de oro ensortijado que el ánima me tienen enlazada, y volved a la nieve no pisada lo blanco de esas rosas matizado.

Dejad las perlas y el coral preciado de que esa boca está tan adornada, y al cielo, de quien sois tan codiciada, volved los soles que le habéis robado.

La gracia y discreción, que muestra ha sido

10 del gran saber del celestial maestro, volvédselo a la angélica natura,

y todo aquesto así restituido, veréis que lo que os queda es propio vuestro: ser áspera, crüel, ingrata y dura.

SOÑÉ QUE DE UNA PEÑA ME ARROJABA...*

Soñé que de una peña me arrojaba quien mi querer sujeto a sí tenía, y casi ya en la boca me cogía una fiera que abajo me esperaba.

Yo, con temor, buscando procuraba de dónde con las manos me tendría; al filo de una espada la una asía, y a una yerba la otra mano echaba.

* APM 1801, ff. 73v-74r, con el título "Soneto de Terrazas". OTras FuENTES: FBP 1980, pp. 206-207, con el título "120. Soneto de Terrazas”; BJG 1863, columna 1003, con el título "Soneto de Terrazas"; y ACL 1941, p. 3, con el numeral "I".

7 codiciada: envidiada BJG 1863| ACL 1941.

* C 193 (1600), f. 58r, con el título "Soneto". Otras Fuentes: APM 1801, ff. 117v-118r, con el título "Soneto de Terrazas"; PHU 1918, pp. 50-51, con el título "Soñé que de una peña me arrojaba..."; FBP 1980, pp. 277-278, con el título "186. Soneto de Terrazas"; y ACL 1941, p. 5, con el numeral "III".

${ }^{6}$ tendría: "Asir, o mantener asida alguna cosa" (DA, t. 6 [1739], s.v. tener).

7 al: y al APM 1801|| y el PHU 1918 | ACL 1941.

8 a una yerba: en una yerbezuela APM 1801| PHU 1918 | ACL 1941 || mano echaba: aba [ilegible en el ms.] APM $1801 \mid$ PHU 1918 || otra hincaba ACL 1941. 
La yerba, a más andar, la iba arrancando;

10 la espada iba la mano deshaciendo, y yo sus crudos filos apretando.

¡Oh, mísero de mí, que mal me entiendo, pues huelgo verme estar despedazando de miedo de acabar mi mal muriendo!

¡AY, BASAS DE MARFIL, VIVO EDIFICIO...!*

¡Ay, basas de marfil, vivo edificio obrado del artífice del cielo, columnas de alabastro que en el suelo nos dais del bien supremo claro indicio!

$5 \quad$ ¡Hermosos chapiteles y artificio del arco que aun de mí me pone celo! ¡Altar donde el tirano dios mozuelo hiciera de sí mismo sacrificio!

¡Ay, puerta de la gloria de Cupido, 10 y guarda de la flor más estimada de cuantas en el mundo son ni han sido! Sepamos hasta cuando estáis cerrada y el cristalino cielo es defendido a quien jamás gustó fruta vedada.

10 iba: a mí APM 1801| PHU 1918| ACL 1941.

11 Om. y APM 1801 || sus crudos: sus vivos APM 1801 || y yo sus crudos: yo más sus vivos PHU 1918 | ACL 1941 || crudos: "Lo que no está pulido ni curado" (DA, t. 2 [1729], s.v. crudo).

* APM 1801, f. 173r-173v, con el título "Soneto de Terrazas". Otras FUENTES: FBP 1980, p. 364, con el título "255. Soneto de Terrazas"; BJG 1863, columna 1007, con el título "Soneto de Terrazas"; y ACL 1941, p. 6, con el numeral "IV".

${ }^{10}$ guarda: "Custodia a alguna cosa" (DA, t. 4 [1734]).

13 es defendido: "Vale también mantener, conservar alguna cosa contra el dictamen o gusto de algunos o muchos" (DA, t. 3 [1732], s.v. defender).

14 vedada: vedado, prohibido, "el campo, u sitio acorado, u cerrado por ley, u ordenanza” (DA, t. 6 [1739]). 
A UNA DAMA QUE DESPABILÓ UNA VELA GON LOS DEDOS*

El que es de algún peligro escarmentado suele temerle más que quien le ignora; por eso temí el fuego en vos, señora, cuando de vuestros dedos fue tocado.

Mas ¿visteis qué temer tan excusado del daño que os hará la vela ahora? Si no os ofende el vivo que en mí mora, ¿cómo os podrá ofender fuego pintado?

Prodigio es de mi daño. Dios me guarde

10 ver el pábilo en fuego consumido, y acudirle al remedio vos tan tarde; señal de no esperar ser socorrido el mísero que en fuego por vos arde hasta que esté en ceniza convertido.

ROYENDO ESTÁN DOS CABRAS UN ÑUDOSO...**

Royendo están dos cabras un ñudoso y duro y seco ramo en la mimbrera, que ya les fue en la verde primavera dulce, süave, tierno y muy sabroso.

* APM 1801, ff. 227v-228r, con el título "Soneto de Terrazas a una dama que despabiló una vela con los dedos". Otras Fuentes: FBP 1980, p. 451, con el título "301. Soneto de Terrazas. A una dama que despabiló una vela con los dedos"; BJG 1863, columnas 1007-1008, con el título "Soneto de Terrazas a una dama que despabiló una vela con los dedos"; y ACL 1941, p. 9, con el título "VII. A una dama que despabiló una vela con los dedos".

${ }^{5}$ visteis: vistes $A P M 1801 \mid$ FBP 1980| BJG 1863.

${ }^{9}$ Prodigio: "Suceso extraño que excede a los límites regulares de la naturaleza". Puede tomarse, al parecer, "por milagro" (DA, t. 5 [1737]).

* C 193 (1600), f. 105r-105v, con el título "Soneto". Otras fuENTEs: APM 1801, ff. 236v-237r, con el título "Soneto de Terrazas"; PHU 1918, p. 51, con el título "Royendo están dos cabras de un nudoso..."; FBP 1980, pp. 465-466, con el título "315. Soneto de Terrazas"; y ACL 1941, p. 4, con el numeral "II".

1 ñudoso: nudoso APM 1801 || un ñudoso: de un nudoso FBP 1980| PHU 1918 | ACL 1941.

${ }^{2}$ y seco ramo: ramo seco APM 1801 | FBP 1980| PHU 1918| ACL 1941. 
$5 \quad$ Sienten el gusto extraño y amargoso; no hallan ramo verde en la ribera, que como su sazón pasada era, pasó también su gusto deleitoso.

$Y$ tras de aquel sabor que echaron menos,

10 de un ramo en otro ramo van mordiendo y quedan sin comer, de porfïadas.

¡Memorias de mis dulces tiempos buenos! ¡Así voy yo en vosotras discurriendo, sin ver sino venturas acabadas!

AQUELLA LARGA MANO QUE REPARTE...*

Aquella larga mano que reparte sus dones y riquezas en el suelo para animarnos al supremo vuelo donde consigo mismo al hombre harte

5 con obras y consejos, y con arte dejó su amor divino por modelo por un dechado de aquel bien del cielo de que hacernos quiso tanta parte.

De aquí es que la amistad sincera y pura

10 no es sólo de los pechos virtüosos más aún divina imagen perfectísima.

Así que si pensarlo te es dulzura, también me causa a mí gloria dulcísima con que olvido los ratos trabajosos.

${ }^{5}$ Sienten el gusto extraño: Hallan extraño el gusto APM $1801 \mid$ FBP 1980 | PHU 1918| ACL 1941.

${ }^{6}$ verde: bueno APM $1801 \mid$ FBP $1980 \mid$ PHU 1918| ACL 1941.

9 de aquel: deste $A P M 1801$ || aquel: este | echaron: echaban APM 1801 | FBP 1980 | PHU 1918 | ACL 1941.

11 porfiadas: "Tercas, obstinadas" (DA, t. 5, [1737]).

13 yo en: tras APM $1801 \mid$ FBP 1980| PHU 1918| ACL 1941 || discurriendo: “Andar, caminar, correr por diversas partes o parajes". En sentido metafórico "vale examinar, pensar y conferir razones que hay en favor o en contra de alguna cosa" (DA, t. 3 [1732], s.v. discurrir).

* C 193 (1600), f. 92r-92v, con el título "Soneto. De Terraças".

${ }^{9}$ la: el $C 193$ (1600).

12 te es dulzura: 'te deleita'. 
